\title{
An integrated approach to diagnosis and management of severe haemoptysis in patients admitted to the intensive care unit: a case series from a referral centre
}

\author{
Muriel Fartoukh* ${ }^{* 1}$, Antoine Khalil ${ }^{\dagger 2}$, Laurence Louis ${ }^{\dagger 1}$, Marie- \\ France Carette $^{\dagger 2}$, Bernard Bazelly ${ }^{\dagger 3}$, Jacques Cadranel ${ }^{\dagger 1}$, Charles Mayaud ${ }^{\dagger 1}$ \\ and Antoine Parrot ${ }^{\dagger 1}$
}

\begin{abstract}
Address: ${ }^{1}$ Service de Pneumologie et Unité de Réanimation Respiratoire, Hôpital Tenon, Assistance Publique - Hôpitaux de Paris and Université Pierre et Marie Curie, 4 Rue de la Chine, 75020 Paris, France, ${ }^{2}$ Service de Radiologie, Hôpital Tenon, Assistance Publique - Hôpitaux de Paris and Université Pierre et Marie Curie, 4 Rue de la Chine, 75020 Paris, France and ${ }^{3}$ Service de Chirurgie Thoracique et Vasculaire, Hôpital Tenon, Assistance Publique - Hôpitaux de Paris and Université Pierre et Marie Curie, 4 Rue de la Chine, 75020 Paris, France

Email: Muriel Fartoukh* - muriel.fartoukh@tnn.aphp.fr; Antoine Khalil - antoine.khalil@tnn.aphp.fr; Laurence Louis - llmezzina@noos.fr; Marie-France Carette - marie-france.carette@tnn.aphp.fr; Bernard Bazelly - bernard.bazelly@tnn.aphp.fr;

Jacques Cadranel - jacques.cadranel@tnn.aphp.fr; Charles Mayaud - charles.mayaud@tnn.aphp.fr; Antoine Parrot - antoine.parrot@tnn.aphp.fr

* Corresponding author †Equal contributors
\end{abstract}

Published: 15 February 2007

Respiratory Research 2007, 8:11 doi:10.1 186/1465-992I-8-II

This article is available from: http://respiratory-research.com/content/8/I/I

(c) 2007 Fartoukh et al; licensee BioMed Central Ltd.

This is an Open Access article distributed under the terms of the Creative Commons Attribution License (http://creativecommons.org/licenses/by/2.0), which permits unrestricted use, distribution, and reproduction in any medium, provided the original work is properly cited.
Received: 13 May 2006

Accepted: 15 February 2007

\begin{abstract}
Background: Limited data are available concerning patients admitted to the intensive care unit (ICU) for severe haemoptysis. We reviewed a large series of patients managed in a uniform way to describe the clinical spectrum and outcome of haemoptysis in this setting, and better define the indications for bronchial artery embolisation (BAE).
\end{abstract}

Methods: A retrospective chart review of 196 patients referred for severe haemoptysis to a respiratory intermediate care ward and ICU between January 1999 and December 200I. A followup by telephone interview or a visit.

Results: Patients (I48 males) were aged 5 I ( \pm sd, 16) years, with a median cumulated amount of bleeding averaging $200 \mathrm{ml}$ on admission. Bronchiectasis, lung cancer, tuberculosis and mycetoma were the main underlying causes. In 21 patients (I I\%), no cause was identified. A first-line bronchial arteriography was attempted in 147 patients (75\%), whereas 46 (23\%) received conservative treatment. Patients who underwent BAE had a higher respiratory rate, greater amount of bleeding, persistent bloody sputum and/or evidence of active bleeding on fiberoptic bronchoscopy. When completed $(n=131 / \mid 47)$, BAE controlled haemoptysis in $80 \%$ of patients, both in the short and long ( $>30$ days) terms. Surgery was mostly performed when bronchial arteriography had failed and/ or bleeding recurred early after completed BAE. Bleeding was controlled by conservative measures alone in 44 patients. The ICU mortality rate was low (4\%).

Conclusion: Patients with evidence of more severe or persistent haemoptysis were more likely to receive BAE rather than conservative management. The procedure was effective and safe in most patients with severe haemoptysis, and surgery was mostly reserved to failure of arteriography and/or early recurrences after BAE. 


\section{Background}

Haemoptysis may present as a life-threatening condition, with a mortality rate reaching $80 \%$ in the absence of adequate and prompt management [1-4]. The criteria used to characterize severe haemoptysis are heterogeneous and ill-defined. They are usually limited to the amount of blood expectorated within 24-48 hrs and its clinical consequences [5], or to the interventions used [6]. A more 'functional' definition accounting for the respiratory reserve has also been proposed [6]. Recent surveys suggest a shift from surgery to bronchial artery embolisation (BAE) as a first-line procedure in severe haemoptysis $[7,8]$. Defining a better standardized management would be useful to physicians in charge of patients with severe haemoptysis to improve outcomes and should preferably take place in or nearby the intensive care unit (ICU).

In this study, we analyzed a large series of unselected patients with severe haemoptysis referred to a single respiratory intensive care unit with an affiliated intermediate care ward. Our objectives were to describe the characteristics of the patients managed using one of the three main initial therapeutic options (conservative measures, BAE or surgery) and to help better define the role of BAE, according to the severity of haemoptysis. The study was conducted in accordance with French law, which does not require approval of an IRB or the consent of patients for such retrospective analysis of medical records.

\section{Patients and methods Patients}

The study was conducted between January 1999 and December 2001 in Tenon hospital, a tertiary university hospital and referral centre for haemoptysis in Paris, France. All consecutive patients admitted to the respiratory intermediate care ward or ICU for severe haemoptysis were eligible. Exclusion criteria were iatrogenic bleeding, bleeding of gastrointestinal and oropharyngeal origin, heart failure, intra alveolar haemorrhage and incomplete data. For each patient, the following information were recorded: baseline demographics, comorbid conditions, initial clinical presentation and vital signs, laboratory tests results, chest radiography, fiberoptic bronchoscopy and CT scan findings when performed, severity of haemoptysis, and pre-ICU and in-ICU management. The persistence or recurrence of bleeding, the patients' ICU and hospital lengths of stay and their vital status at discharge were recorded, as well as the occurrence of long-term rebleeding. Patients with recurrent haemoptysis were included at the first episode only.

\section{Definitions}

\section{Severity of haemoptysis}

The severity of haemoptysis on admission was assessed according to (i) the cumulated amount of bleeding; (ii) the consequences of bleeding; (iii) and the presence of associated severe cardiovascular and pulmonary comorbidities. The cumulated amount of bleeding on admission was assessed from the onset of bleeding until the first hours of admission to our unit using the following standardized scale: a spoonful (5 ml), a small filled glass (100 $\mathrm{ml})$ and a large filled glass $(200 \mathrm{ml})$. The consequences of bleeding were assessed on the need for administration of local or systemic terlipressin, mechanical ventilation, vasoactive drugs or blood transfusions before referral or within the first 24 hours of ICU admission.

\section{Cause of haemoptysis}

The cause of haemoptysis was diagnosed on the combination of history, physical examination, chest radiography, fiberoptic bronchoscopy, CT scan, microbiology and histology when available. Definite causes were bronchiectasis (including inactive tuberculosis), active tuberculosis, cancer and mycetoma. Pulmonary venous thromboembolic disease, pneumonia and emphysema were classified as probable causes. Haemoptysis was considered cryptogenic when no cause was evidenced.

\section{Course of haemoptysis}

Immediate control of bleeding was defined as a cessation of bleeding obtained without recurrence until hospital discharge, whatever the therapeutic option used. Rebleeding was defined as the persistence and/or the recurrence of bleeding after treatment. Early-onset rebleeding was defined as occurring within the first 30 days, and lateonset as rebleeding after one month.

\section{Management}

Our approach to initial management favoured conservative measures and BAE over surgery, whenever possible. Conservative measures included strict bed rest, nothing by mouth, and continuous monitoring of oxygen saturation, respiratory rate, heart rate and arterial blood pressure. Oxygen was delivered to obtain a pulse oxymetry value > 90\%; two large-bore intravenous lines were inserted and all medications potentially increasing the risk of bleeding were stopped. Broad-spectrum antibiotics were frequently administered and no attempt was made to suppress cough. Bronchoscopic techniques were attempted to control the bleeding, using cold saline solution lavage, instillation of topical vasoconstrictive agents and/or balloon tamponade therapy. As the administration of systemic terlipressin may interfere with the success of BAE, its use was avoided whenever possible.

The selection of BAE as the first-line approach was based on the presence of severity criteria on admission. A standardized BAE procedure was used as follows: a catheter was introduced into the right femoral artery through an introducer sheath using the Seldinger technique. A 5-French 
pigtail catheter (Angioflex, biosphere medical, Roissy, France) with the tip located at the origin of the ascending aorta was used, and $40 \mathrm{ml}$ of contrast medium was administered at $20 \mathrm{ml} / \mathrm{s}$. Selective bronchial artery angiography was then performed, using catheters ranging from 5 to 6.5 French. Embolisation was performed when the bronchial arteries appeared to be the source of haemoptysis (tortuous hypertrophy, systemic-to-pulmonary shunting, extravasation of contrast material, or peribronchial hypervascularisation) or when they had a near-normal aspect but supplied the site of bleeding identified by fiberoptic bronchoscopy and/or CT scan. The material used for embolisation was 400 - to $1000-\mu \mathrm{m}$ polyvinyl alcohol particles and/or gelfoam. A visualisation of an anterior spinal artery arising from an intercostal artery deriving from the right bronchointercostal trunk was considered an absolute contraindication to embolisation. Microcatheters were not used at the time of the study. BAE was considered successful when bleeding stopped immediately after embolisation.

\section{Statistical analysis}

The patients' demographics, clinical variables and laboratory data were analyzed using usual descriptive statistics. Results were expressed as mean \pm standard deviation (range), unless otherwise stated. Between groups comparisons used the Man Whitney $U$ test for categorical variables, and the chi square test for nominal variables. A p value below 0.05 was considered statistically significant.

\section{Results}

\section{Demographics, clinical features and biology}

During the three-year study period, 230 consecutive patients were referred to our unit for severe haemoptysis. Thirty-four patients (15\%) were excluded because of bleeding secondary to bronchial biopsies $(\mathrm{n}=1)$, digestive tract bleeding $(n=1)$, pharyngeal bleeding $(n=1)$, heart failure $(\mathrm{n}=3)$, intra alveolar haemorrhage $(\mathrm{n}=2)$ and incomplete data $(n=26)$. Overall, 196 patients were thus included in this study. Most patients ( $\mathrm{n}=149,76 \%)$ were referred to our unit from another hospital for consideration of BAE within 24 hours after hospital admission $(1 \pm 1.8$ days; median 0$)$ because haemoptysis persisted or worsened. The patients (148 males) were 51 years old. Cough, persistent bloody sputum and dyspnea were the main respiratory symptoms on admission. Physical examination revealed localized crackles in $60 \%$ of the cases (Table 1). There were mild biological consequences of bleeding regarding blood spillage and gas exchanges (Table 2).

\section{Severity of haemoptysis}

Chronic obstructive pulmonary $(\mathrm{n}=50,26 \%)$ and/or cardiovascular $(\mathrm{n}=53,27 \%)$ disease were frequently recorded. Using our scale, the mean cumulated volume of blood loss averaged $240 \pm 200 \mathrm{ml}$ on admission to our unit (range, 10 to $1000 \mathrm{ml}$; median $200 \mathrm{ml}$ ) (Figure 1). Active tuberculosis, cancer and mycetoma were associated with a larger volume as compared with the cryptogenic group $(\mathrm{p}=0.03 ; \mathrm{p}=0.03$ and $\mathrm{p}=0.003$, respectively; Figure 2.). There were severe consequences of bleeding in 73 patients $(37 \%)$ leading to the following interventions prior to the referral or during the first 24 hours of ICU admission: local $(\mathrm{n}=23)$ or systemic $(\mathrm{n}=56)$ terlipressin, mechanical ventilation $(\mathrm{n}=17)$, blood transfusion $(\mathrm{n}=$ $22)$, vasoactive drugs support $(n=3)$ or cardiopulmonary resuscitation $(n=2)$. Patients receiving the above mentioned interventions had a higher respiratory rate on admission $(24 \pm 7 v$ s. $21 \pm 6$ per min; $\mathrm{p}=0.04)$, a higher heart rate $(91 \pm 20 v s .85 \pm 20 \mathrm{bpm} ; \mathrm{p}=0.04)$, a lower room air partial pressure of oxygen in arterial blood (73 \pm 15 vs. $80 \pm 17 \mathrm{~mm} \mathrm{Hg}$; $\mathrm{p}=0.03)$, a higher cumulated volume of blood loss $(360 \pm 240 \mathrm{ml} v$ s. $180 \pm 150 \mathrm{ml}$; p < $0.0001)$, and a lower haemoglobin value $(11.5 \pm 2.6 v s$. $13.3 \pm 2 ; \mathrm{p}<0.001)$; they also had more often active bleeding on bronchoscopy $(31 / 68$ vs. 22/114, p = $0.0003)$, a first-line attempt at bronchial arteriography (66/73 vs. 81/123; $\mathrm{p}<0.0001)$, a need for surgery (25/73 vs. 9/123; $\mathrm{p}<0.0001)$ and specific aetiologies [mycetoma (11/73 vs. 3/123; $\mathrm{p}=0.002)$ and cancer (22/73 vs. 11/123; $\mathrm{p}<0.001)$ ], but not a higher frequency of cardiovascular and pulmonary pre-existing diseases.

\section{Cause of haemoptysis}

Bronchiectasis $(\mathrm{n}=78,40 \%)$, lung cancer $(\mathrm{n}=33,17 \%)$, active tuberculosis $(\mathrm{n}=27,14 \%)$ and mycetoma $(\mathrm{n}=14$, $7 \%)$ accounted for $87 \%$ of all causes. Emphysema $(n=10$, $5 \%)$, pneumonia $(n=6,3 \%)$, pulmonary embolism $(n=$ $2,1 \%)$ and miscellaneous causes $(n=5,3 \%)$ accounted for the remaining probable causes. In 21 patients (11\%), no cause was evidenced. The cause of bleeding was identified in $69 \%(\mathrm{n}=111 / 162)$ of patients at bedside when combining history, comorbid conditions, physical examination, chest-X-Ray and fiberoptic bronchoscopy findings, as compared with $91 \%(\mathrm{n}=148 / 162)$ after a further CT scan $(\mathrm{p}<0.001)$. The CT scan examination was especially useful for diagnosing bronchiectasis.

\section{Management}

All patients received conservative measures. Local $(n=6)$ or systemic $(\mathrm{n}=37)$ terlipressin, mechanical ventilation $(\mathrm{n}=3)$ and blood transfusion $(\mathrm{n}=3)$ were administered to the most severe patients before referral. Forty-three $(22 \%)$ patients were receiving aspirin, coumadin or clopidrogel that may have worsened the bleeding, and these drugs were temporarily stopped whenever possible. Broad-spectrum antibiotics were administered to 153 patients (78\%). A fiberoptic bronchoscopy was performed within 24 hours of bleeding onset in most patients $(n=184,94 \%)$. Diffuse and bilateral $(n=13)$ or 
Table I: Clinical characteristics on ICU admission.

\begin{tabular}{|c|c|}
\hline Age, years & $51 \pm 16(17-89)$ \\
\hline Sex Ratio (male:female) & $148: 48(3.1: 1)$ \\
\hline SAPS II score & $18 \pm 9(6-48)$ \\
\hline McCabe and Jackson categories, $\mathrm{n} *$ & $133 / 46 / 13$ \\
\hline Cumulated volume of hemoptysis, $\mathrm{ml} \dagger$ & $240 \pm 200(10-1000)$ \\
\hline$<200 \mathrm{ml}, \mathrm{n}(\%)$ & $86(45 \%)$ \\
\hline$\geq 200 \mathrm{ml}, \mathrm{n}(\%)$ & $107(55 \%)$ \\
\hline Heart rate, $/ \mathrm{min}$ & $87 \pm 20(48-150)$ \\
\hline$>130 / \mathrm{min}, \mathrm{n}(\%)$ & $10(5 \%)$ \\
\hline Systolic Arterial Pressure, $\mathrm{mm} \mathrm{Hg}$ & $135 \pm 28(76-221)$ \\
\hline$<100 \mathrm{~mm} \mathrm{Hg}, \mathrm{n}(\%)$ & $9(5 \%)$ \\
\hline Spontaneous Ventilation, n (\%) & $179(91 \%)$ \\
\hline Mechanical Ventilation [Invasive/Non Invasive], n (\%) & $17[16 / 1](9 \%)$ \\
\hline Core Temperature, ${ }^{\circ} \mathrm{C}$ & $37.3 \pm 0.8(36-40)$ \\
\hline$>38.5^{\circ} \mathrm{C}, \mathrm{n}(\%)$ & $18(9 \%)$ \\
\hline \multicolumn{2}{|l|}{ Respiratory functional signs } \\
\hline Cough, n (\%) & $116(73 \%)$ \\
\hline Persistent bloody expectoration, $\mathrm{n}(\%)$ & 107 (69\%) \\
\hline Dyspnea, $n(\%)$ & $121(66 \%)$ \\
\hline Purulent expectoration, $\mathrm{n}(\%)$ & $10(6 \%)$ \\
\hline Chest pain, $\mathrm{n}(\%)$ & II (6\%) \\
\hline \multicolumn{2}{|l|}{ Physical examination } \\
\hline At least one localized abnormality, $n(\%)$ & $94(48 \%)$ \\
\hline Crackles, $\mathrm{n}$ & $59(63 \%)$ \\
\hline
\end{tabular}

Results are expressed as mean \pm SD (range), unless otherwise stated.

$* 4$ missing data; $\nmid 3$ missing data.

Table 2: Biological variables on ICU admission.

\begin{tabular}{|c|c|}
\hline Blood Leukocytes Count, mm³ & $9183 \pm 3543(1500-25300)$ \\
\hline Platelets Count, $\mathrm{mm}^{3}$ & $258464 \pm 105195(45000-7 \mid 2000)$ \\
\hline$<100000 / \mathrm{mm}^{3}, \mathrm{n}(\%)$ & $6(3 \%)$ \\
\hline Hemoglobin, g/dl & $12.6 \pm 2.4(4.6-18.3)$ \\
\hline$<10 \mathrm{~g} / \mathrm{dl}, \mathrm{n}(\%)$ & $29(15 \%)$ \\
\hline Prothrombin Time, \% & $88 \pm 16(11-118)$ \\
\hline$\leq 50 \%, \mathrm{n}(\%)$ & $7(4 \%)$ \\
\hline Activated partial thromboplastin time ratio & $\mathrm{I} . \mathrm{I} \pm 0.2(0.7-2.2)$ \\
\hline$\geq 1.5$ control, $\mathrm{n}(\%)$ & $7(4 \%)$ \\
\hline Nitrogen Urea, mmoles/l & $5.5 \pm 2.7(1-19)$ \\
\hline$\geq 10$ mmoles $/ \mathrm{l}, \mathrm{n}(\%)$ & $12(6 \%)$ \\
\hline \multicolumn{2}{|l|}{ Blood gas on room air * } \\
\hline $\mathrm{PaO}_{2}, \mathrm{~mm} \mathrm{Hg}$ & $78 \pm 17(43-100)$ \\
\hline $\mathrm{PaCO}_{2}, \mathrm{~mm} \mathrm{Hg}$ & $39 \pm 5(26-63)$ \\
\hline $\mathrm{pH}$ & $7.43 \pm 0.05(7.30-7.50)$ \\
\hline $\mathrm{SaO}_{2}, \%$ & $95 \pm 4(76-99)$ \\
\hline
\end{tabular}

Results are expressed as mean \pm SD (range), unless otherwise stated.

*data available for 142 patients. 


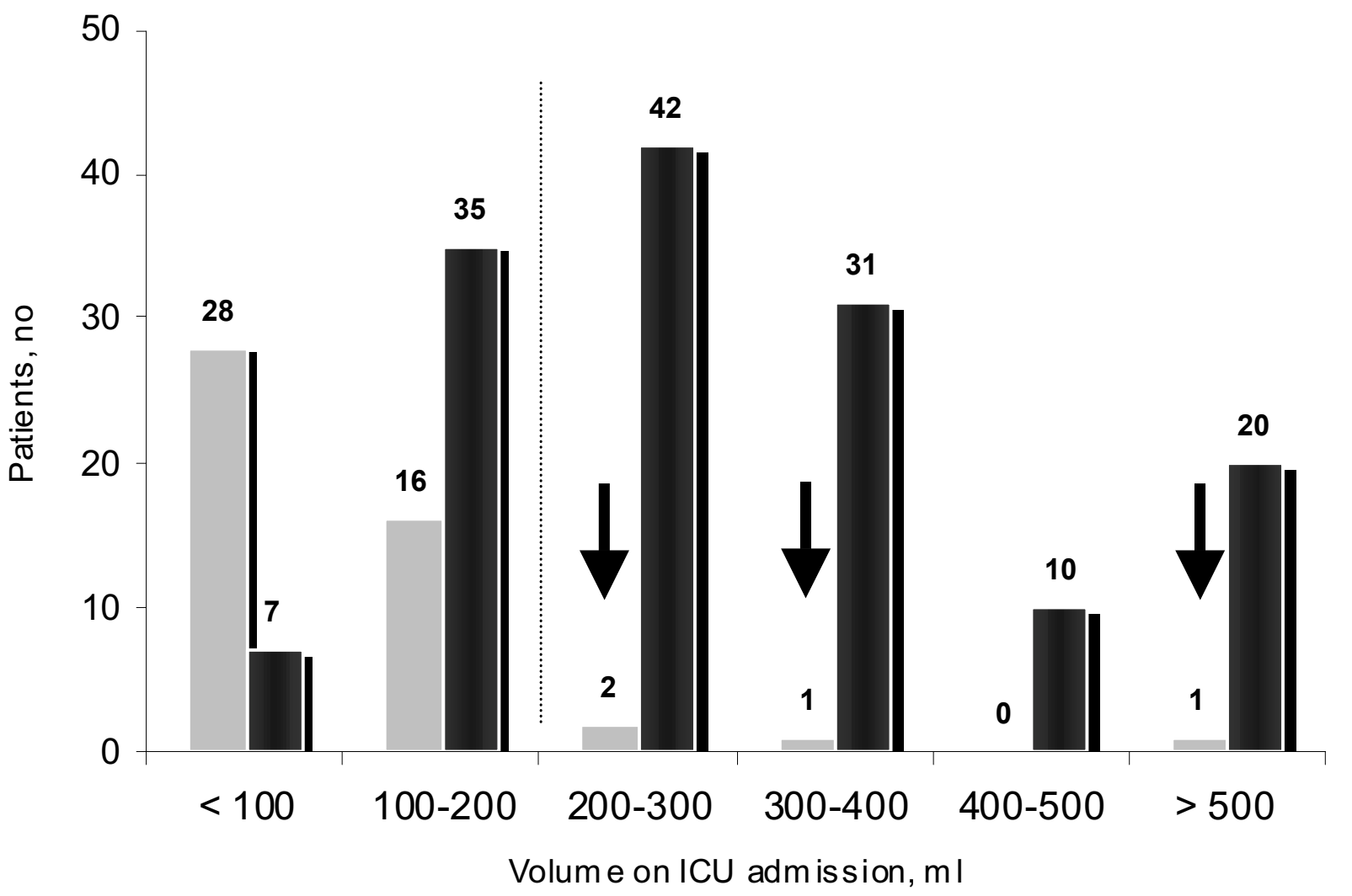

No first-line bronchial arteriography

First line bronchial arteriography

Figure I

Distribution of the cumulated volume of haemoptysis on ICU admission, according to the first attempt of bronchial arteriography. Bronchial arteriography was not attempted in 4 patients with a volume $\geq 200$ ml: one patient with moderate renal insufficiency (cryptogenic haemoptysis of $200 \mathrm{ml}$ ) received conservative treatment and emergency surgery was performed in the 3 other patients.

localized endobronchial bleeding $(\mathrm{n}=163)$ was evidenced in 176 patients (96\%). The bronchoscopic findings revealed a localized active endobronchial bleeding in 53 patients and a localized endobronchial clotting in 41 . Otherwise, a localized endobronchial bleeding was evidenced in the upper $(n=43)$ or lower bronchia $(n=26)$ without active bleeding or clotting. In the remaining 8 patients (4\%), a few signs of endobronchial blood were present. Bronchoscopic techniques were combining blood aspiration and local instillation of cold saline lavage. Vasopressors were bronchoscopically delivered in 23 patients, and a balloon was placed in one patient.

A first-line bronchial arteriography was attempted in 147 patients $(75 \%)$, whereas $46(23 \%)$ received conservative treatment. Emergency surgery was performed in 3 patients (bleeding of $700 \mathrm{ml}$ revealing a cancer complicated by a cardiac arrest; bleeding of $300 \mathrm{ml}$ revealing a cancer nearby the pulmonary artery; bleeding of $200 \mathrm{ml}$ complicating repeated obstructive pneumonias in a patient diagnosed with a cancer) (Figure 3 ). The following parameters on admission were associated with the first attempt of arteriography as opposed to conservative treatment alone: a higher respiratory rate $(23 \pm 7 v s .20 \pm 4 ; \mathrm{p}=0.03)$, a greater amount of bleeding $(290 \pm 205 v$ s. $80 \pm 50 ; \mathrm{p}<$ $0.0001)$, a persistent bloody sputum (87/119 vs. $18 / 35$; $\mathrm{p}$ $=0.02)$, an active bleeding on bronchoscopy (49/141 vs. $3 / 36 ; \mathrm{p}=0.002)$, the identification of a definite cause of haemoptysis (120/149 definite causes vs. 9/21 cryptogenic; $\mathrm{p}=0.0005$ ) and the absence of renal impairment (creatinin, $\mu \mathrm{mol} / \mathrm{l} ; 73 \pm 22$ vs. $82 \pm 25 ; \mathrm{p}=0.03$ ).

Technical failure of the attempted arteriography occurred in $15 / 147(10 \%)$ patients, mostly those with mycetoma 


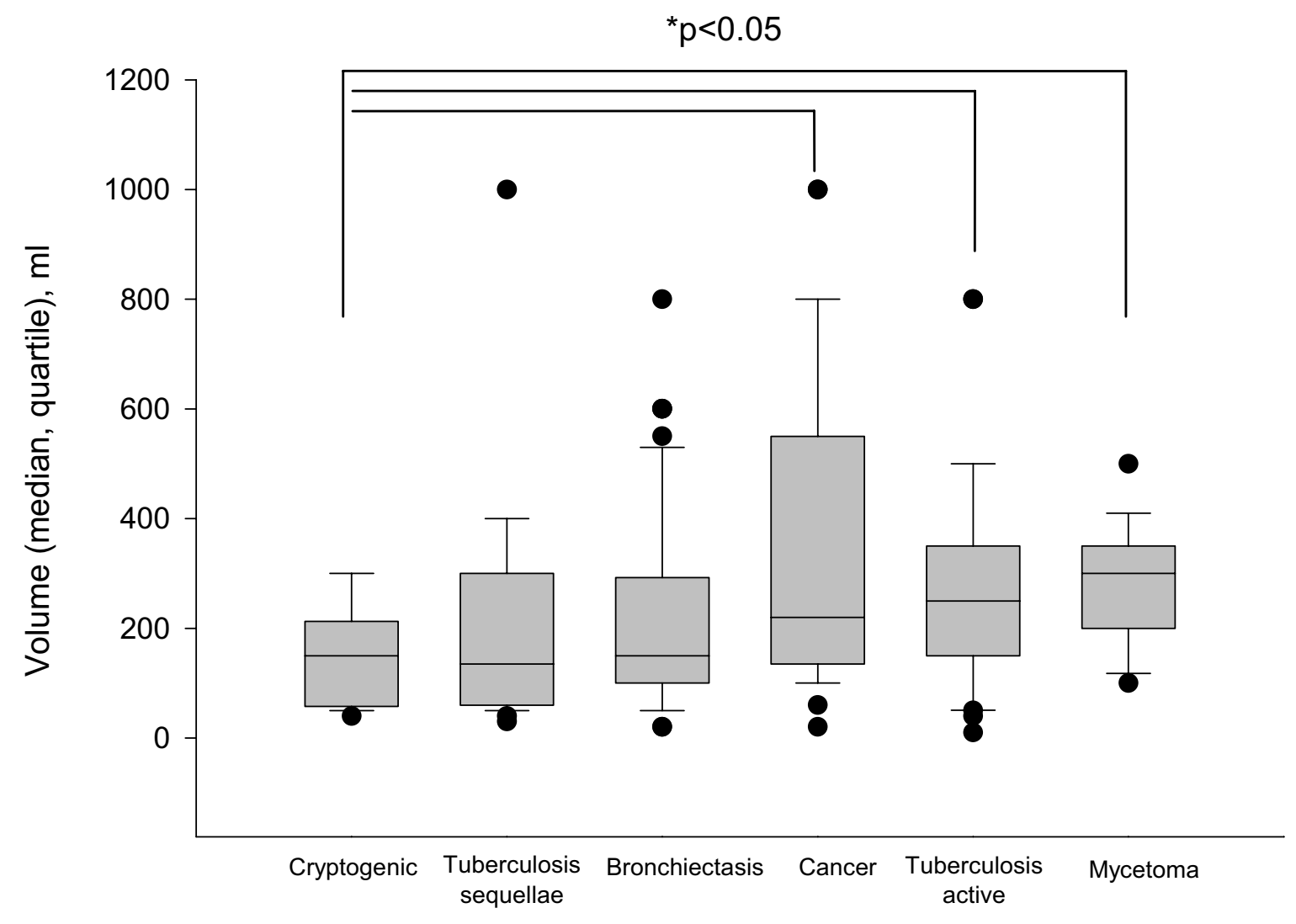

Cause

Figure 2

Distribution of the volume of haemoptysis (median, quartile) on admission according to the cause. Plots of the median, 10th, 25th, 75th, and 90 th percentiles as vertical boxes with error bars.

$(n=4)$ and cancer $(n=6)$. This led to either maintaining conservative measures in 9 patients or to surgery in six; 5 of these 15 patients died within the first month (4/9 patients managed conservatively and $1 / 6$ undergoing surgery). In another patient, bleeding was related to a pulmonary artery aneurysm. Bronchial artery embolisation was eventually completed in 131/147 patients (89\%) leading to an immediate control of bleeding in 106 patients $(81 \%), 8$ of whom had a secondary scheduled surgery (Figure 3).

Bleeding recurred in $7 / 46$ patients $(15 \%)$ managed conservatively, 2 of whom received BAE secondarily. Bleeding recurred in 35/131 patients (27\%) receiving completed BAE. Haemoptysis recurred after $3 \pm 3$ days (range, 0 to 11 days) in 25 patients, who received conservative treatment $(n=4)$, BAE $(n=7)$ or surgery $(n=14)$. Mycetoma and cancer accounted for $50 \%$ of the early recurrences. There were 10 late recurrences ( $9 \pm 4$ months; range, 2 to 14 months) managed conservatively $(n=4)$ or with a second BAE $(n=3)$ or surgery $(n=3)$. Overall, surgery (pneumonectomy, $\mathrm{n}=3$; lobectomy, $\mathrm{n}=11$ ) was performed after 7 \pm 7.5 days for early recurrences (mycetoma, $\mathrm{n}=6$; bronchiectasis, $\mathrm{n}=3$; pneumonia, $\mathrm{n}=3$; cancer, $\mathrm{n}=2$ ). A lobectomy was performed for late recurrences $12 \pm 5$ months after the initial episode.

Bronchial artery embolisation was associated with a $5 \%$ rate of complications (minor arterial dissection, $\mathrm{n}=2$; coronary ischemia, $\mathrm{n}=2$; chest pain, $\mathrm{n}=1$; transient neuro- 


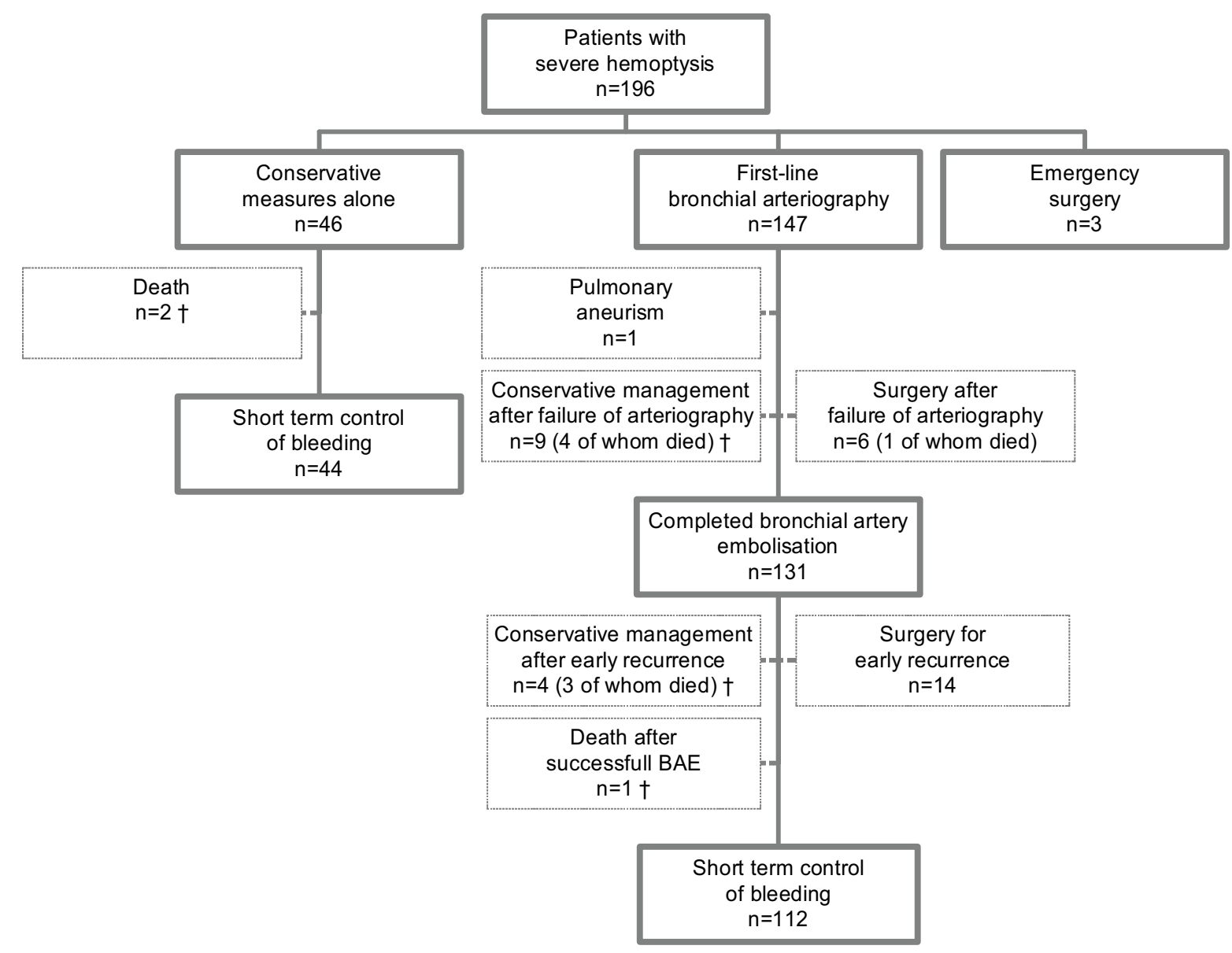

Figure 3

Initial management and short-term outcome. †Life sustaining therapy was withheld/withdrawn in 2/46 patients managed conservatively and in 10/147 patients in whom BAE was first attempted.

logical episode, $\mathrm{n}=1$; and dysphagia; $\mathrm{n}=1$ ). The outcome of these patients was uneventful without further intervention.

\section{Outcome}

The lengths of ICU and hospital stay were respectively 5.4 \pm 4.9 days (range, 0 to 47 days) and $10.7 \pm 14$ days (range, 0 to 142 days). Lengths of ICU $(6 \pm 5.4$ days $v s .3 .8 \pm 2.5$ days) and hospital stay ( $11 \pm 14.4$ days $v s .8 .8 \pm 12.4$ days $)$ were significantly longer for patients in whom a bronchial arteriography was first attempted, as compared with patients receiving conservative treatment alone (all p < $0.01)$. Therapy was withheld or withdrawn in 12 patients $(6 \%), 7$ of whom died in ICU. The ICU and hospital mortality rates were $4 \%(n=8)$ and $8 \%(n=15)$, respectively.
At short term follow-up (one month), successful control of haemoptysis was obtained using completed BAE, conservative management or surgery in respectively 112 (57\%), $44(22 \%)$ and 22 (11\%) patients. No recurrence of haemoptysis occurred in $116(89 \%)$ of the 131 patients in whom BAE was completed, after a mean (median) followup duration of 20 (8) months.

\section{Discussion}

Our study aimed at characterizing the clinical spectrum and the outcome of a large series of consecutive patients with severe haemoptysis requiring ICU admission in the early 2000's. The major aetiologies recorded were bronchiectasis, lung cancer, active tuberculosis and mycetoma. A simple set of clinical variables on admission combined 
with bronchoscopic findings were associated with attempting a first-line bronchial arteriography. This approach was applicable to $75 \%$ of our patients and led to an immediate control of bleeding in more than $80 \%$ of them. Although the median cumulated volume of haemoptysis averaged $200 \mathrm{ml}$ on admission, the ICU mortality rate was low.

Haemoptysis accounted for up to $15 \%$ of our admissions. This high rate reflects in part the fact that both our unit and the department of radiology of our hospital are referral centres for haemoptysis. The major criterion for ICU admission is the amount of blood loss despite the lack of standardisation for quantifying it, since it is known to be related to death [5]. Respiratory failure, a substantial drop of haemoglobin level, and haemodynamic failure all obviously mandate ICU admission, although their occurrence is not specified in most studies. While the usual criteria of severity accounted for a relatively small subset of our patients, the median cumulated volume of haemoptysis averaged $200 \mathrm{ml}$ on admission and chronic obstructive pulmonary disease and cardiovascular disease were frequent.

Bronchiectasis, active tuberculosis and idiopathic haemoptysis were the most frequent diagnoses among a French cohort of 56 patients with life-threatening haemoptysis recorded between 1986 and 1996 [6]. In a small recent series of 29 patients with massive haemoptysis requiring ICU admission in Singapore between 1997 and 2001, bronchiectasis, mycetoma, active tuberculosis and cancer were the main causes identified [9]. In our series, bronchiectasis (mainly secondary to inactive tuberculosis), cancer, active tuberculosis and mycetoma were the leading causes. Such a distribution of the causes of haemoptysis underlines the following points: 1) First, active tuberculosis still remains a common cause of severe haemoptysis in France; 2) Lung cancer appears to be an emerging cause of haemoptysis requiring ICU admission. The latter finding is at variance with previous studies by Mal et al. [6] and Ong et al. [9], which may be related to the smaller number of patients included in those previous studies $[6,9]$, the study period [6] and the geographic location [9], as well as the current lesser restrictive policy for ICU admission of cancer patients.

The indications of emergency surgery have gradually been reduced, because of the reported $20-30 \%$ operative mortality rate and improvement in interventional radiology techniques $[1-4,10]$. Bronchial artery embolisation is now considered as the most effective non-surgical first-line treatment of severe haemoptysis [11,12], although there is no randomized trial in this field. Bronchoscopy-guided topical haemostatic tamponade therapy has also been demonstrated to control haemoptysis with varying suc- cess rates, using flexible or rigid bronchoscope for the instillation of procoagulant substances, local injection of adrenalin solutions, insertion of small calibre catheters or placement of oxidized regenerated cellulose [13].

In our series, a bronchial arteriography was first attempted in $75 \%$ of patients, whereas only $2 \%$ underwent emergency surgery. A relatively large subset of our patients $(23 \%)$ was managed conservatively, based on our approach to assess the amount of blood loss and other criteria of severity on admission. Technical failure of arteriography has been reported in up to $20 \%$ of attempts, although a lower rate is expected with the use of micro catheters in the near future [6,9,14-17]. Moreover, bleeding recurrences after successful completed BAE range from $0 \%$ to $30 \%$ and may be influenced by the cause of haemoptysis [18-20]. In our series, the rate and causes of bronchial arteriography failure were similar. Haemoptysis recurred in $27 \%$ of patients. There were mostly early recurrences, two thirds of which were eventually controlled by surgery. According to an 'intent to treat analysis', a firstline arteriography was associated with an immediate control and a durable cessation of bleeding in 112 (57\%) and 116 (59\%) patients, respectively. Although other series reported higher immediate successful rates of BAE for controlling haemoptysis, ranging from $85 \%$ to $95 \%$ $[16,18,20]$, it should be noted that no information was provided on patients in whom the procedure was not completed [21]. In our series, bleeding was controlled in $112 / 131$ patients $(85 \%)$ within the first month and in $116 / 131$ patients $(89 \%)$ after hospital discharge, when the procedure was completed.

Using a strategy including a routine assessment of the amount of bleeding with a standardized scale, and promoting BAE over surgery, the outcomes of patients were good. The ICU mortality rate was low, as reported in recent series of so-called life-threatening haemoptysis [6].

The limitations of our study are related to its retrospective nature and to the fact that it was conducted in a referral centre with an extensive experience of severe haemoptysis on a heterogeneous patients' group. Nevertheless, our study reports one of the largest series of medical inpatients over a short time period and may provide a useful framework for the therapeutic management of haemoptysis in this clinical setting.

To summarize, a multidisciplinary approach remains the cornerstone for the management of severe haemoptysis. Bedside clinical evaluation and early fiberoptic bronchoscopy may safely screen patients for initial BAE, including surgical candidates. In the latter, surgery should be postponed as much as possible during active bleeding and performed early after control of bleeding. Otherwise, surgery 
should be reserved to cases of failure of interventional radiology and/or uncontrolled bleeding despite embolisation. Further prospective studies are needed to confirm the safety and the reproducibility of such a therapeutic approach; this approach may also be influenced by the use of the multi detector row helical CT scan, which can depict accurately the bronchial and non bronchial arteries, prior to the embolisation.

\section{Competing interests}

The author(s) declare that they have no competing interests.

\section{Financial support}

None

\section{Authors' contributions}

Dr Fartoukh had full access to the data and takes responsibility for the integrity of the data and the accuracy of the data analysis.

Study concept and design: Fartoukh, Cadranel.

Acquisition of data: Parrot, Louis, Fartoukh.

Analysis and interpretation of data: Fartoukh, Parrot, Mayaud, Cadranel.

Drafting of the manuscript: Fartoukh, Parrot, Carette, Khalil.

Critical revision of the manuscript for important intellectual content: Parrot, Khalil, Carette, Bazelly.

Statistical analysis: Fartoukh, Parrot, Cadranel.

Study supervision: Fartoukh.

\section{References}

I. Crocco JA, Rooney JJ, Fankushen DS: Massive hemoptysis. Arch Intern Med 1968, I $21: 495-498$.

2. Garzon AA, Gourin A: Surgical management of massive hemoptysis. Ann Surg 1977, 137:267-27I.

3. Garzon AA, Gourin A: Surgical management of massive hemoptysis: a 10-year experience. Ann Surg 1978, 187:267-27I.

4. Sehhat $S$, Oreizie M, Moinedine K: Massive pulmonary hemorrhage: surgical approach as choice of treatment. Ann Thorac Surg 1978, 25:12-15.

5. Dweik RA, Stoller JK: Role of bronchoscopy in massive hemoptysis. Clinics in chest medicine 1999, 20:89-105.

6. Mal H, Rullon I, Mellot F, Brugiere O, Sleiman C, Menu Y, Fournier M: Immediate and long-term results of bronchial artery embolization for life-threatening hemoptysis. Chest 1999, I I 5:996-100I.

7. Haponik EF, Chin R: Hemoptysis: clinicians' perspectives. Chest 1990, 97:469-475

8. Haponik EF, Fein A, Chin R: Managing life-threatening hemoptysis. Has anything really changed? Chest 2000, I 18:143।-1435.

9. Ong TH, Eng P: Massive hemoptysis requiring intensive care. Intensive Care Med 2003, 29:317-320.

10. Gourin A, Garzon AA: Operative treatment of massive hemoptysis. Ann Thorac Surg 1974:52-60.
II. Remy J, Arnaud A, Fardou H: Treatment of hemoptysis by embolization of bronchial arteries. Radiology 1977, I 22:33-37.

12. Lordan JL, Gascoigne A, Corris PA: The pulmonary physician in critical care. Illustrative case 7: assessment and management of massive haemoptysis. Thorax 2003, 58:8।4-819.

13. Valipour A, Kreuzer A, Koller H, Koessler W, Burghuber OC: Bronchoscopy-guided topical hemostatic tamponade therapy for the management of life-threatening hemoptysis. Chest 2005, 127:21|3-2|18.

14. Rabkin JE, Astafjef VI, Gothman LN: Transcatheter embolization in the management of pulmonary hemorrhage. Radiology 1987, 163:36|-365.

15. Ufkacker R, Kaemmerer A, Picon PD: Bronchial artery embolisation in the management of hemoptysis: technical aspects and long-term results. Radiology 1985, 157:637-644.

16. Cremaschi P, Nascimbene C, Vitulo P: Therapeutic embolization of bronchial artery: a successful treatment in 209 cases of relapse hemoptysis. Angiology 1993, 44:295-299.

17. Tanaka N, Yamakado K, Murashima S, Takeda K, Matsumura K, Nakagawa T, Takano K, Ono M, Hattori T: Superselective bronchial artery embolization for hemoptysis with a coaxial microcatheter system. J Vasc Interv Radiol 1997, 8:65-70.

18. Hayakawa K, Tanaka F, Torizuka T: Bronchial artery embolization for hemoptysis: immediate and long-term results. Cardiovasc Intervent Radiol 1992, I 5: 154-159.

19. Knott-Craig CJ, Oostuizen JD, Rossouw G: Management and prognosis of massive hemoptysis. J Thorac Cardiovascular Surg 1993, 105:394-397.

20. Ramakantan R, Bandekar VG, Gandhi MS: Massive hemoptysis due to pulmonary tuberculosis: control with bronchial artery embolization. Radiology 1996, 200:691-694.

21. White RI: Bronchial artery embolotherapy for control af acute hemoptysis. Chest 1999, I 15:912-915.

Publish with Bio Med Central and every scientist can read your work free of charge

"BioMed Central will be the most significant development for disseminating the results of biomedical research in our lifetime. "

Sir Paul Nurse, Cancer Research UK

Your research papers will be:

- available free of charge to the entire biomedical community

- peer reviewed and published immediately upon acceptance

- cited in PubMed and archived on PubMed Central

- yours - you keep the copyright
BiolMedcentral 